\title{
Lunch at the library: examination of a community-based approach to addressing summer food insecurity
}

\author{
Janine S Bruce*, Monica M De La Cruz, Gala Moreno and Lisa J Chamberlain \\ Stanford University School of Medicine, 1265 Welch Road, X240, Stanford, CA 94305, USA
}

Submitted 24 August 2016: Final revision received 18 January 2017: Accepted 24 January 2017: First published online 20 March 2017

\begin{abstract}
Objective: To examine a library-based approach to addressing food insecurity through a child and adult summer meal programme. The study examines: (i) risk of household food insecurity among participants; (ii) perspectives on the library meal programme; and (iii) barriers to utilizing other community food resources.

Design: Quantitative surveys with adult participants and qualitative semi-structured interviews with a sub-sample of adult participants.

Setting: Ten libraries using public and private funding to serve meals to children and adults for six to eight weeks in low-income Silicon Valley communities (California, USA) during summer 2015.

Subjects: Adult survey participants ( $\geq 18$ years) were recruited to obtain maximum capture, while a sub-sample of interview participants was recruited through maximum variation purposeful sampling.

Results: Survey participants ( $n$ 161) were largely Latino (71\%) and Asian (23\%). Forty-one per cent of participants screened positive for risk of food insecurity in the past 12 months. A sub-sample of programme participants engaged in qualitative interviews ( $n$ 67). Interviewees reported appreciating the library's child enrichment programmes, resources, and open and welcoming atmosphere. Provision of adult meals was described as building community among library patrons, neighbours and staff. Participants emphasized lack of awareness, misinformation about programmes, structural barriers (i.e. transportation), immigration fears and stigma as barriers to utilizing community food resources. Conclusions: Food insecurity remains high in our study population. Public libraries are ideal locations for community-based meal programmes due to their welcoming and stigma-free environment. Libraries are well positioned to link individuals to other social services given their reputation as trusted community organizations.
\end{abstract}

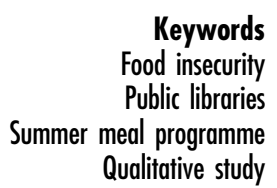

Keywords

Public libraries Qualitative study
Food insecurity (FI) in the USA is a leading public health challenge in terms of the national scope and severity of consequences $^{(1)}$. During the Great Recession families throughout the country reported unprecedented rates of $\mathrm{FI}^{(2)}$. In $2015,12 \cdot 7 \%$ of US households (15.8 million households) were food insecure at some time during the year, meaning that individuals experienced limited or uncertain access to adequate food as a result of lack of money and other resources. Approximately 6.3 million of these food-insecure households experienced 'very low' food security, resulting in individuals going hungry or skipping meals ${ }^{(3)}$. Some households are at higher risk for FI, including those with incomes near or below the federal poverty level, Black and Hispanic households ${ }^{(4)}$, and households headed by a single parent ${ }^{(3)}$, individuals with low education ${ }^{(5)}$ or immigrant mothers ${ }^{(6)}$.

The Great Recession had a disproportionate impact on children, as the fractions of children living in poverty and in food-insecure households increased markedly ${ }^{(2)}$. In $2015,7 \cdot 8 \%$ of households with children ( 3 million households) were food insecure, with parents reporting lack of access to resources to provide adequate, nutritious food for their children ${ }^{(3)}$. When compared with childless households, those with children were nearly twice as likely to be food insecure ${ }^{(7)}$. Among children who experienced 'very low' food security, parents or guardians often cited occasions when children went hungry, skipped meals or did not eat for the whole day because the household/family could not afford enough food ${ }^{(2,8)}$. While recovery from the recession is beginning to be felt across the USA, FI among children remains persistently high $^{(9,10)}$.

FI among children has been shown to be associated with poor physical and behavioural outcomes such as inadequate intakes of important nutrients ${ }^{(11,12)}$, cognitive developmental delays $^{(13-15)}$ and psychosocial dysfunction ${ }^{(14-16)}$. Children who are food insecure suffer from poor overall health ${ }^{(17,18)}$ 
that has lasting effects into adulthood ${ }^{(7,19)}$. Additionally, household FI has been demonstrated to increase the risk of maternal mental health problems including depression, stress and anxiety, poor physical health, and current or past substance use $\mathrm{(}, 20-22)^{(T)}$ These negative outcomes for mothers can in turn have a detrimental impact on children, amplifying the consequences of FI on entire families ${ }^{(23)}$.

The US government recognizes the importance of preventing FI in children. Multiple national nutrition assistance programmes have been created to provide essential safety nets for children and families. One of the most prominent and important nutrition safety-net programmes for children is the National School Lunch Program (NSLP), created in 1946, that serves approximately 32 million children annually $^{(7,24,25)}$. Among children participating in the NSLP, many live in low-income households and qualify for free $(<130 \%$ of the federal poverty level) or reduced-price meals (130-185\% of the federal poverty level) ${ }^{(26)}$.

Unfortunately, this programme is not reaching all of the children in need, particularly during the summer months when children have decreased access to free and reduced-price meals, and child FI rates increase as caregivers struggle to stretch limited budgets during the break ${ }^{(8,25,27)}$. The federal Summer Food Service Program (SFSP) was established in 1975 to bridge the summer meal gap by reimbursing providers (i.e. schools, non-profit agencies, camps, etc.) for providing lunches and snacks to low-income eligible children during the school break ${ }^{(28)}$. Despite widespread utilization of free and reduced-price meals during the school year, only 3.8 million children participated in summer meal programmes in $2014^{(28)}$, highlighting the difficulty of reaching children during the summer ${ }^{(29)}$.

\section{Library-based meal programmes}

Emerging evidence suggests the role of public libraries in providing essential social services during periods of recession. Libraries play a vital role in helping individuals and communities by providing access to information, resources and support during periods of economic hardship $^{(30,31)}$. They are trusted community organizations ${ }^{(31,32)}$ with a mission to cultivate healthy minds and healthy bodies $^{(33)}$. They are flexible to community needs, responding to changing social issues and demands ${ }^{(31)}$. To address summer FI, libraries across the country began serving lunches to low-income children throughout the summer, with one of the earliest documented programmes starting at an Oakland (California) public library in $2011^{(34)}$. Given that libraries are natural places where children and families congregate during the summer to participate in summer enrichment programmes, to utilize resources and in some cases to avoid the heat ${ }^{(29)}$, serving meals is a natural extension of their mission. Over the last several years, the number of library meal sites has increased and participation by children has gone up exponentially ${ }^{(29)}$.
Despite the growing involvement of libraries in providing meals to low-income children, no current studies examine the role of library-based meal programmes in addressing FI. While a majority of community-based meal programmes offer only child meals due to SFSP eligibility restrictions, the present study focused on libraries that utilized SFSP funding for child meals but also leveraged private funding to provide adult meals as well. The aim of the study was to: (i) screen for risk of FI among meal programme participants; (ii) gain participants' perspectives on the library meal programme; and (iii) examine barriers to accessing and utilizing other community food resources.

\section{Methods}

Quantitative and qualitative methods were used to examine the meal programmes at ten library sites located in highpoverty areas in Silicon Valley in California. Each library was deemed eligible to participate in the SFSP based on US Department of Agriculture eligibility requirements, which stipulate that ' $50 \%$ or more of children residing in the area must be eligible for free or reduced-price meals, ${ }^{, 28)}$. In addition to using SFSP funding to provide unlimited child meals, participating libraries also used private funding from the local children's hospital and food bank to provide adult meals during lunchtime. Outreach for the meal programme included recruiting through libraries, word of mouth, and in some cases flyers distributed through schools prior to the end of the school year.

\section{Quantitative data collection and analysis}

From June to August 2015, adult meal programme participants ( $\geq 18$ years old) were recruited by library staff to complete an anonymous self-administered survey in English, Spanish or Vietnamese. The aim was to obtain maximum capture across each of the ten library sites. However, it should be noted that meal programme participants were not individually tracked through the lunch programme, so a standard sample size and response rate were not able to be determined. Surveys were distributed multiple days during the data collection period to give participants many opportunities to complete the voluntary survey. Child meal programme participants were excluded from the study.

The surveys were designed to obtain participant demographic data, screen for the risk of household FI, assess meal programme utilization, and examine access and utilization of other community-based food resources (i.e. pantries, hot meals and public safety-net programmes such as the Supplemental Nutrition Assistance Program (SNAP)). Demographic questions were adapted from the California Health Interview Survey ${ }^{(35)}$ and a validated two-item screener was used to determine risk for FI in the last 12 months ${ }^{(36)}$. Participants were considered at risk for FI 
if they answered affirmatively to one or both of the FI questions. The research team and community stakeholders developed and pilot-tested the remaining access and utilization questions before professionally translating and administering the surveys. Survey data were analysed using the statistical software package IBM SPSS Statistics ${ }^{\circledR}$ Version 24.0. Data were stratified by ethnicity, household type and education to determine possible associations between risk for FI and participant characteristics using the $\chi^{2}$ test of independence.

\section{Qualitative data collection and analysis}

A sub-sample of survey participants was asked to voluntarily participate in anonymous one-on-one interviews from July through August 2015. A semi-structured interview guide was developed to examine the primary domains covered in the survey and to elicit a more in-depth examination of participants' perceptions on the library-based meal programme.

Given the potential heterogeneity of programme participants, maximum variation purposeful sampling was used to capture a range of common perspectives and experiences $^{(37)}$. This involved library staff recruiting a wide range of programme participants to be interviewed, including adults attending the meal programme with or without children, and individuals with regular or sporadic attendance. Interviews were conducted on varying days of the week and times throughout the summer to allow for as diverse a sample as possible, with participation limited to approximately six individuals per site. Interviews lasted 20-30 min and were conducted in English, Spanish or Vietnamese based on participant preference. Interview participants received a \$US 15 Target gift card for participating.

English interviews were audio-recorded and transcribed verbatim by a transcription service. Spanish and Vietnamese interviews were also audio-recorded, transcribed and translated by members of the analysis team. Coding software (Dedoose $^{(}$) was used to organize data and facilitate the analysis process ${ }^{(38)}$. A codebook was developed inductively and subsequently applied to the transcripts by the research team through an iterative process of reviewing and highlighting coded excerpts to identify relevant themes for each broad topic area ${ }^{(39-41)}$. The coders obtained a final inter-rater reliability Cohen's $\kappa$ score of $0 \cdot 85$. The research team then analysed the coded data to identify emergent themes. Multiple themes were similarly generated through an iterative process among the analysis team and representative quotes identified $^{(42)}$. The incorporation of multiple perspectives throughout the critical review process was designed to assess and check the potential influence and biases of the study authors and to strengthen the interpretation and credibility of the data ${ }^{(43)}$.

Given the anonymous nature of the surveys and interviews, a waiver of documentation for consent was granted by the Stanford Institutional Review Board. During recruitment, participants received a study information sheet in English, Spanish or Vietnamese and provided verbal consent to participate.

\section{Results}

In 2015, the ten participating Silicon Valley libraries held meal programmes during the lunch period five days per week for six to eight weeks during the summer break. The libraries provided meals to children, their accompanying parent(s) and other adults not accompanied by a child. During this period approximately 18000 meals were served to children (12600 meals) and adults (5600 meals) across the participating libraries.

\section{Quantitative survey findings}

Survey participants ( $n$ 161) completed the surveys in English (57\%), Spanish (39\%) or Vietnamese (4\%). The majority of participants self-identified as Latino/Hispanic (71\%) or Asian (23\%). Most participants reported living in two-parent/ adult-led households (78\%) followed by single-parent/adultled households (15\%), with only a small number reporting that their households were headed by a grandparent or other guardian (7\%). Only fifteen (9\%) survey participants reported that they did not have children living in their household, suggesting that very few participants were adults not accompanied by a child. Thirty-three per cent of survey participants noted that the head of their household had either a bachelor's or graduate degree, which contrasted with nearly one-quarter of participants who had completed some high school or less (23\%; Table 1).

\section{Food insecurity and utilization of community food resources}

Forty-one per cent of participants screened positive for risk of FI at some time in the past 12 months. There were statistically significant $(P \leq 0.05)$ relationships between risk of FI and race/ethnicity, household type and number of adults in the household. Among those at risk for FI, the vast majority ( $85 \%$ ) were Latino/Hispanic. Sixty-seven per cent of those at risk for FI were from two-parent households and $25 \%$ were from single-parent households. Most foodinsecure participants were from households with two adults (61\%) present. FI status was not significantly correlated with participant education level; however, $21 \%$ of those who were food insecure did hold a bachelor's or graduate degree (Table 1).

The majority of participants attended the library meal programme regularly. Forty-three per cent of participants attended the lunch programme 1-2 d/week, 27\% attended 3-4 d/week and $21 \%$ attended every day. The vast majority of participants reported that they did not experience any barriers to attending the library meal programme. Additionally, we surveyed participants' knowledge and use of food resources within the community. Thirty per cent knew of places to get hot meals, pantry items or fresh 
Table 1 Characteristics and food insecurity among library meal programme participants from low-income communities in Silicon Valley, California, USA, summer 2015

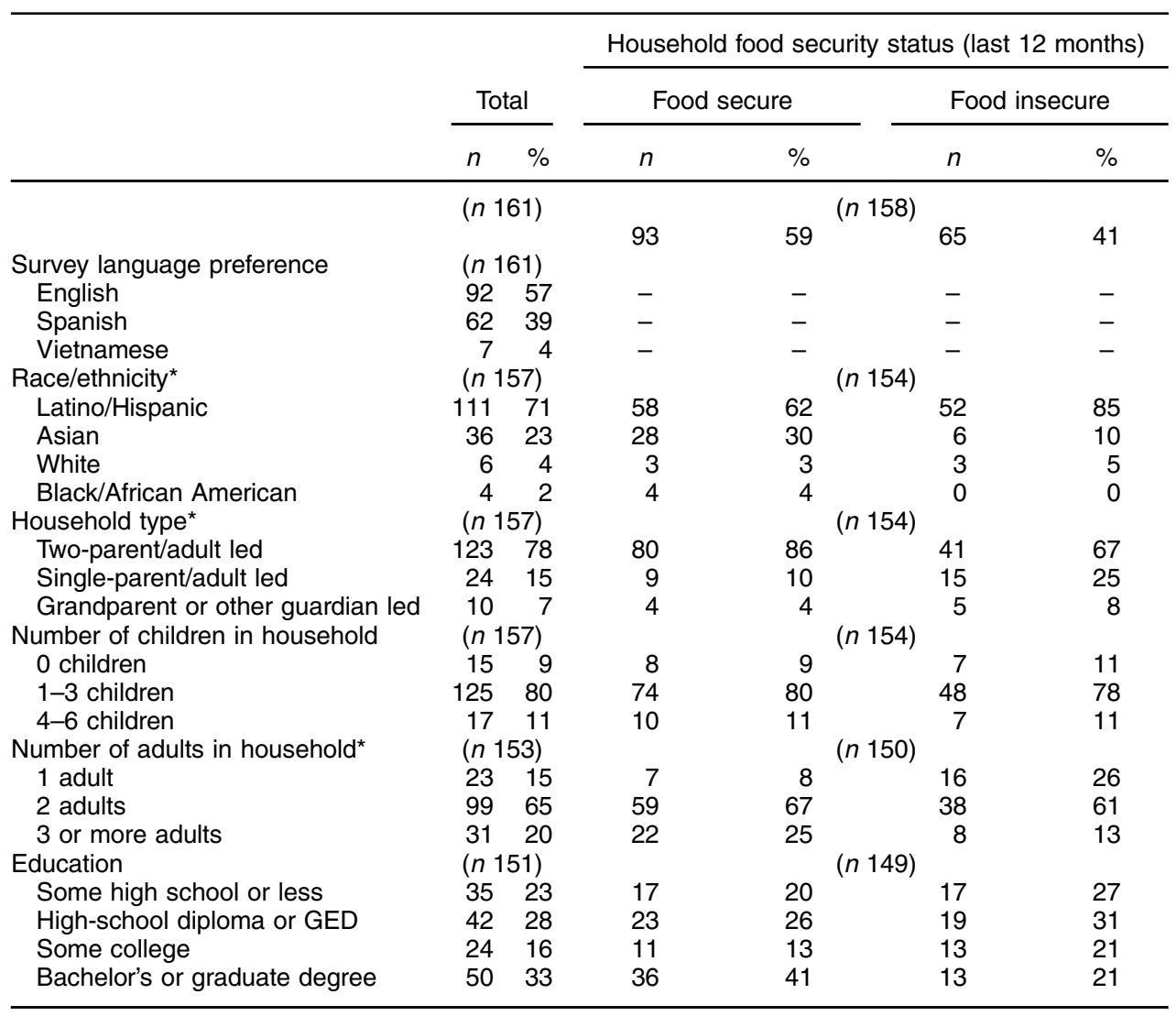

GED, General Educational Development.

Some totals do not equal the total sample size due to differences in response rates. ${ }^{*}$ Statistically significant at $P \leq 0.05$.

produce in their community, but among this group only $68 \%$ had used these resources in the past. We also asked about participants' knowledge and use of SNAP. While the majority of participants knew of SNAP (71\%), only $21 \%$ were enrolled and $16 \%$ indicated that they were ineligible at the time of the survey (Table 2).

\section{Qualitative interview findings}

A sub-sample of sixty-seven adults (accompanied by children and without children) attending the meal programme participated in qualitative interviews conducted in Spanish (54\%), English (42\%) and Vietnamese (4\%). Participants were primarily Latino/Hispanic (67\%), with a small proportion of Asian (16\%) and White (8\%) individuals. Seventy-six per cent of interviewees lived in two-parent households, $13 \%$ in single-parent households and $11 \%$ in homes without children. The interview participants were demographically consistent with the survey participants.

\section{Domain 1. Library meal programme}

Theme 1: Libraries provide an open and welcoming atmosphere. When asked to share overall perceptions of the library meal programme, participants highly valued the 'openness' of the library. Many noted that they appreciated that the library was open to all and there were no requirements that needed to be met to participate. One Latina female participant noted, 'It's a relaxing place to be. I like that it's open to everybody and there's so many resources here available for everybody. It's a nice place to come to.' Additionally, participants cited the welcoming atmosphere fostered by library staff, which reinforced the 'openness' of the library and strengthened the overall perception of the programme. Participants specifically appreciated the friendly and respectful atmosphere conveyed by the library staff (Table 3 ).

Since the library meal programmes in the present study provided meals to both children and adults, participants discussed an overall feeling of inclusiveness as a result of the adult meals. Parent and adult participants valued the ability to eat with children and other community members. Parent participants specifically noted that eating with their children strengthened family bonds. Even adult participants who did not have children appreciated the family atmosphere that the library meal programme fostered.

A few participants described the library as feeling like 'home' when they were there, particularly with all of the 
Table 2 Library meal programme participation and utilization of community programmes among participants from low-income communities in Silicon Valley, California, USA, summer 2015

\begin{tabular}{|c|c|c|}
\hline & $n$ & $\%$ \\
\hline \multicolumn{3}{|l|}{ Library meal programme participation } \\
\hline Estimated weekly attendance & \multicolumn{2}{|c|}{$(n$ 160) } \\
\hline Every day & 34 & 21 \\
\hline $3-4 \mathrm{~d} /$ week & 43 & 27 \\
\hline $1-2 \mathrm{~d} /$ week & 69 & 43 \\
\hline Did not regularly attend programme & 14 & 9 \\
\hline $\begin{array}{l}\text { How participants learned about programme } \\
\text { (multiple sources selected) }\end{array}$ & \multicolumn{2}{|c|}{$(n 159)$} \\
\hline Flyer from child's school & 20 & - \\
\hline Flyer from library & 63 & - \\
\hline Flyer from community agency & 8 & _ \\
\hline Heard from friends & 52 & - \\
\hline Library website & 10 & - \\
\hline Other source & 30 & - \\
\hline $\begin{array}{l}\text { Barriers to programme participation } \\
\text { (multiple barriers selected) } \dagger\end{array}$ & \multicolumn{2}{|c|}{$(n 158)$} \\
\hline No barriers & 124 & - \\
\hline Getting to site was difficult & 3 & _ \\
\hline Lunch times were inconvenient & 9 & - \\
\hline Inability to stay and eat & 5 & - \\
\hline Did not like food offered & 8 & _ \\
\hline Other difficulties & 17 & - \\
\hline Knowledge and utilization of community programmes & & \\
\hline $\begin{array}{l}\text { Knowledge of other food programmes (i.e. pantries, } \\
\text { hot meals, etc.) }\end{array}$ & \multicolumn{2}{|c|}{ (n 154) } \\
\hline Yes & 47 & 30 \\
\hline $\begin{array}{l}\text { If yes (knowledgeable), past use of other food } \\
\text { programmes }\end{array}$ & 32 & 68 \\
\hline Knowledge of SNAP & \multicolumn{2}{|c|}{ (n 156) } \\
\hline Yes & 110 & 71 \\
\hline Enrolled in SNAP & $(n 15)$ & \\
\hline Yes & 33 & 21 \\
\hline No & 101 & 63 \\
\hline Ineligible & 25 & 16 \\
\hline
\end{tabular}

SNAP, Supplemental Nutrition Assistance Program.

Some totals do not equal the total sample size due to differences in response rates.

†Determination of percentages not applicable.

children around. In the words of one female participant, 'I enjoy being with the children. I feel like I'm home, at this particular branch.' Another participant enjoyed that the library provided an atmosphere where people from the community could come together to teach and learn from one another: 'We meet here. It's like [a] home away from home [like] your house.'

Theme 2: Enrichment programmes in conjunction with meals is a strength. Participants noted the benefit of coming to the library for the many different services and resources that it offers. While the participating library meal sites varied in terms of the specific programmes offered to children and adults, most participants acknowledged that the library was a place that they came to read, check out materials, use the computer, engage their children in literacy activities, and in some cases have their children participate in structured summer camps.

The enrichment programmes provided at the library offered opportunities to engage children while preventing summer learning loss. While only a few participants said that they came to the library specifically for the meal programme, once at the library, they enjoyed the many resources that the library had to offer.

Parent participants specifically appreciated the opportunity the library provided for their children to socialize with other children. Parents also felt that coming to the library for the enrichment programmes and the lunch was a way to get their children 'out of the house' and participating in active play and socialization with other children in the community. Such interactions were seen as a chance to help prepare children for other similar social interactions in their future.

Some adult participants not attending the meal programme with children valued the social interaction during the meals. They appreciated the chance to be around other adults during the meal programme and to develop social networks with other community members and neighbours.

Theme 3: Libraries are valuable resource bubs. Libraries were seen not only as a place to build community, but also as a place to obtain valuable resource information. Some participants noted that the library is a place they go to obtain information regarding community resources, events, classes and enrichment programmes. Libraries were believed to offer much more than traditional library resources such as books, videos and computers. Libraries were viewed as a central place in the neighbourhood to congregate and gain access to needed information and resources, particularly for those without other standard means of gaining information.

Theme 4: Economic benefit of library meal programme. Many participants appreciated the economic benefits of attending the library meal programme. They believed the meal programme provided an economic support to the community at large and they appreciated that the programme was open to everyone. Some noted how other community-based meal programmes are limited to children or have specific requirements for participation. Many participants discussed the ways in which it had helped them 'stretch their budget' during the summer break. Having to pay for fewer meals during the summer was viewed as a way to divert savings to other household or family needs.

\section{Domain 2. Access to and utilization of other community} food resources

Theme 1: Lack of awareness about community food resources. Similar to survey findings, some participants noted a lack of awareness of available community food resources such as food pantries, hot meals and public safety-net programmes (i.e. Special Supplemental Nutrition Program for Women, Infants, and Children (WIC) and SNAP). When asked to describe where people in the community seek additional food assistance, several participants noted that they did not know of places to go or how to obtain services or resources. There was also a perceived lack of awareness regarding which programmes 
Table 3 Themes and representative quotes among library meal programme participants $(n 67)$ from low-income communities in Silicon Valley, California, USA, summer 2015

Domain 1. Library meal programme

Theme 1: Libraries provide an open and welcoming atmosphere

'The way this community is served, this branch, serves the community. I understand that this is different than the other one. But it's good so far ... Personally I like the way that this branch treats the people, the community.' (Latina/African American female participant)

'I think it's a turn off when parents aren't allowed to also enjoy the meal with their children. It's a communal thing. So that was what I was talking about and here, it seems like it's open for everybody and there's no age bracket. It's just open.' (Asian female participant)

Theme 2: Enrichment programmes in conjunction with meals is a strength

'I am thankful for the lunch but for me, the most personally important [aspect] is the programme, so that the child is not watching too much television, that he shares more with other children and he learns how to live with different children that are not his classmates, that he can take hold of different experiences and every day would be something different, but l'm thankful also for the lunch [programme].' (Latina female participant)

'There are programmes to come to read [and to] learn the computer ... The children play with each other. So when they go to school in the future, they'll be more comfortable. At home they're very sad. I come here for those reasons and for them to eat together with the free lunch programme. The children have an opportunity to be together, talk to each other, and eat together.' (Vietnamese female participant)

Theme 3: Libraries are valuable resource hubs

'There are many resources but many people don't know about it. Here in the library is my point of .... information, the library, so l've learned through the library ... of health, food, of everything, this is my point of reference, and I think that any library has this, but this is mine specifically.' (Latina female participant)

Theme 4: Economic benefit of library meal programme

'I like that it is a service that they give to the community for nothing, without a fee, or anything. It is a service and helps many parents, like there is a mother who brought her four kids! It also saves me money when I can take fruits and vegetables. It helps me economically.' (Latina female participant)

Domain 2. Access to and utilization of other community food resources

Theme 1: Lack of awareness about community food resources

'Having the family become aware that these specific programmes are there for them. Regardless of their ... legal status here, or their gender or their race. Some of them are not really informed. They [families] are very ... secluded [isolated from resources].' (Latina/ African American female participant)

Theme 2: Incorrect information about existing resources and programme eligibility

'I had heard on the radio how it is easier to qualify for SNAP than before. I was trying to tell her [a friend] what I had heard ... [and] she said, "Oh, well, someone told me ... [that I won't qualify for food stamps]" ... What I have gathered from the conversations is that [people] don't try hard enough to go and know [learn about resources] for themselves. They just believe whatever the neighbour says about how things work.' (Latina female participant)

Theme 3: Structural and economic barriers to programme access

'I have many friends that, well I see that the rent has increased a lot, and honestly ... sometimes they say "no you don't qualify for food stamps" [SNAP] because you earn too much, and that might be reflected in the cheque but ... in reality ... you have to pay for housing, there's a ton of things.' (Latina female participant)

'I think I would qualify for the WIC [programme], but I didn't really want to do it [apply] because they said you have to come, give an exam, [and] they have to measure the kids or something. I don't know, it just didn't feel comfortable, maybe it's not for me ... I just didn't want to do that.' (White female participant)

Theme 4: Immigration fears and stigma associated with programme utilization

I've heard about [SNAP] but my husband doesn't want us to get them [benefits] because he thinks it will be harder to get [immigration] papers ... I come here [to the library meal programme] behind his back because he says that it will affect our [immigration] process.' (Latina female participant)

'When I went over there [to the community agency], the lady ... went from trying to help me to thinking she knew what I wanted. But she did not understand me, and she did not act professionally. She had labelled me [negatively] as someone who used government resources ... If you are working with the community you have to show them respect just like they would any other person with money in their hands.' (Latina female participant)

SNAP, Supplemental Nutrition Assistance Program; WIC, Special Supplemental Nutrition Program for Women, Infants, and Children.

were accessible to those who were not citizens or legal residents, and which programmes were thought to be welcoming to diverse populations. A few participants believed that immigrants were less knowledgeable and connected to resources due to lack of time in the USA and fewer social connections (Table 3).

Schools were cited as a regular source of information regarding community resources; however, some participants noted receiving less information during the summer. There was the perception that programmes existed, but that during the summer, families did not have the same access to information as during the school year. This temporal information loss was worse in families who did not frequent other community programmes or organizations during the summer. One Latina female participant said, 'Sometimes they [the schools] send information [home] with children, but ... one doesn't know what's going on [during the summer].' 
Theme 2: Incorrect information about existing resources and programme eligibility. Some participants said that the information they receive regarding food resources (i.e. pantry times, locations and eligibility) was often incorrect or outdated. They added that individuals in the community often rely too heavily on social networks (i.e. family, peers and neighbours) for information, even when such information was frequently inaccurate. Information regarding programmes with more specific eligibility requirements (i.e. WIC, SNAP) was particularly problematic when such requirements were passed from person to person. The reliance on 'word of mouth' was perceived to be a significant barrier to programme knowledge, as it was believed that some individuals are unable or unwilling to directly seek out accurate information from knowledgeable agencies and organizations due to lack of time or worries about immigration status.

Theme 3: Structural and economic barriers to programme access. For participants who knew of food resources in their communities, many still cited significant barriers to accessing and utilizing those resources. Several participants discussed structural barriers that prevent them from getting food assistance, such as administrative complexities, lack of adequate transportation and long distances to programme sites. Some programme requirements were seen as cumbersome or overly invasive. Other participants viewed the application process for various programmes to have extremely long and complicated paperwork required to apply. For example, SNAP was believed to require a lot of paperwork that was to be completed by prospective applicants themselves, with little outside assistance. One Latina female participant said, "The paperwork [for SNAP] is a lot ... because when they sent me the packet to my house it was very thick; it was a lot of work.'

Some participants shared examples of experiences where they did not qualify for programmes due to lack of income eligibility (overly high incomes), despite the perceived need for assistance. The increasingly high cost of rent and other necessities was cited as contributing to FI despite income ineligibility for food assistance programmes.

Theme 4: Immigration fears and stigma associated with programme utilization. Fear of jeopardizing one's immigration status was noted as a roadblock to applying for community and public programmes and a barrier to accessing needed food resources. Some participants believed that applying for food assistance (i.e. SNAP, WIC) would expose their residency status to government agencies and lead to deportation. A Latina female participant said, 'If you ask for that kind of help [SNAP] the children are compromised, you can't take them out of the country or the state will take them away.'

Participants also discussed stigma as a barrier to obtaining food resources, describing negative experiences with programme staff that discouraged families from obtaining services. A few participants recounted the stigmatizing experiences with food resource programmes associated with issues of racial prejudice. A perceived lack of respect and kindness from such programmes was also widely documented among participants. Some participants described being surprised that they would be treated in such a disrespectful way by agency staff who claimed to want to help.

\section{Discussion}

Despite the apparent wealth of the Silicon Valley in California, areas of high poverty persist and the food security needs of isolated populations are high. The library meal programmes in the present study targeted children and adults visiting libraries situated in low-income communities across the region. Survey participants reported a high risk of household FI, which many interview participants attributed to the extremely high cost of living and the disproportionally large percentage of household income required for housing. This is in line with previous studies showing that as housingrelated costs increase, money available for food expenditures decreases ${ }^{(44,45)}$. Although our study did not quantitatively assess changes in FI associated with programme participation, other studies demonstrate reductions in the prevalence of summer FI associated with summer meals through the $\operatorname{SFSP}^{(27)}$. Similarly, interview participants in our study qualitatively reported economic benefits associated with participation in the library meal programme, noting that it allowed them to stretch summer budgets. It is expected that the programme provided at least a modest subsidy for household meal costs during the summer break. However, future studies should examine changes in FI associated with community-based summer meal programmes.

\section{Libraries: a welcoming and stigma-free environment}

Reaching families living in isolated pockets of poverty is challenging. Libraries situated in low-income communities have the potential to capture some of the hardest-to-reach children and families because of their accessibility and relative distribution across communities irrespective of income. Whether individuals are coming to the library to access information and resources or to utilize enrichment programming, no eligibility is required to use the library. Similarly, the child and adult library meal programme was open to all, with no requirements to participate. Eliminating stringent eligibility requirements and arduous enrolment processes inherent in other food assistance programmes can reduce many of the well-documented administrative barriers to participation in social safety-net programmes such as SNAP and increase programme uptake as a result ${ }^{(46-49)}$.

The libraries' provision of free summer meals through an 'open site' model allowed library patrons to participate without requiring assessments for eligibility. Several study participants mentioned past reluctance to enrol in food assistance programmes due to immigration fears. 
This is particularly important in largely immigrant communities, where fear of enrolment in social programmes is high and poses a deterrent to utilization of services ${ }^{(50-52)}$. Libraries have the potential to better reach immigrant populations given their long history and tradition of providing resources and education to underserved populations ${ }^{(53)}$, particularly individuals seeking help finding jobs, housing and educational opportunities ${ }^{(54)}$. Removing administrative barriers and providing an accessible open site enhance the libraries' ability to engage and support hard-to-reach populations.

The 'home-like' atmosphere conveyed by library staff was cited as one of the most positive aspects of the summer meal programme. Participants appreciated the library meal programme because library staff were friendly and everyone was welcome. The inclusive nature of libraries helped to reduce stigma among participants, as everyone at the library during the lunch period was able to receive a free meal regardless of income, age or immigration status. Stigma associated with participation in safety-net programmes such as SNAP has been found to be a major deterrent to programme participation ${ }^{(55)}$, due to shame and disrespectful treatment when accessing services ${ }^{(46,56)}$. The welcoming and stigma-free environment created by libraries is consistent with the library's inherent culture outlined in the Library Bill of Rights that states, 'A person's right to use a library should not be denied or abridged because of origin, age, background, or views $^{,(57)}$. The library culture effectively breaks down many of the traditional barriers to meal programme participation, making libraries ideal for addressing FI in an environment where people from all backgrounds and socio-economic circumstances can eat together.

Unique to the library meal programmes in the present study was the provision of meals to both children and adults. To our knowledge, no other library-based summer meal programmes provide meals to adults due to SFSP restrictions ${ }^{(28)}$. The libraries in the present study leveraged private funding from the local children's hospital and food bank to provide free adult meals, which created a unique and inclusive summer meal programme model. There was a sense that feeding children and adults together builds community among library patrons, neighbours and staff as meals are shared. The challenge occurs when the summer meal programmes end, but FI persists. Some libraries in our study are discussing the feasibility of providing year-round 'supper' meals to children after school, using federal funds. The problem lies with the private funding for the adult meals, which is more limited in nature. The impact of reducing or eliminating meals after summer should be explored from the perspective of programme participants and library staff.

\section{Libraries: a bub for community resources}

To better understand individuals' ability to access and utilize other community food resources (i.e. pantries, hot meals and public safety-net programmes such as SNAP), participants were asked to share past experiences with such programmes. A primary barrier cited by many participants was a general lack of awareness of existing resources. Among participants who knew about existing food programmes, many cited problems obtaining correct information regarding programme services, eligibility, hours and locations. Other studies have similarly demonstrated how the lack of sufficient information is a considerable barrier to programme participation ${ }^{(47,51,56,58)}$. Also documented is a disproportionate impact on immigrants, who avoid obtaining programme information directly from agencies and instead rely heavily on information provided by social networks and through word of mouth, which can amplify the spread of misinformation $^{(59,60)}$.

The trusted and stigma-free nature of libraries well positions them to be important hubs of information for external community programmes and resources. It is well established that a core purpose of public libraries is to provide local residents with free access to a wide range of information that serves diverse community needs ${ }^{(31,57)}$. Library staff are viewed as knowledgeable experts and trusted sources of information about community programmes and organizations. As such, libraries are uniquely suited to partner with external agencies and organizations and expand the scope of the resources provided at libraries ${ }^{(53,57,61)}$. As individuals begin to view libraries as part of the social safety net, more will turn to libraries and library staff for critical linkages to other community resources and services. Situating meal programmes at public libraries can further strengthen individuals' access to information regarding important food and social resources such as WIC and SNAP. It is important to note, however, that it is likely challenging for librarians and staff to oversee federal SFSP sponsorship requirements and implement daily meal programmes in addition to their traditional roles and responsibilities. Further studies are needed to examine the perception of library staff regarding their role in providing meals at the library and promoting greater access to community food resources.

\section{Limitations}

Findings from the present study are limited in that they can only be generalized to participants from the participating Silicon Valley library meal sites. We recognize that our study population is not representative of individuals participating in other community-based meal programmes. Nor are the findings reflective of individuals not able to participate in a meal programme that provides child and adult meals, as most library meal programmes are limited to child participants. As such, the attitudes regarding the open and welcoming nature of the library meal programme may be different in settings where adults are not able to eat alongside children due to funding restrictions. Additionally, we were not able to capture accurate sample size and response rates for the survey and interview participants. Due to the manner in which the SFSP requires documentation of meals consumed rather than 
individual participant counts, we were not able to report these data. Our study findings may be further biased by the meal programme outreach strategies that primarily relied on library-based outreach as opposed to larger community-based strategies. Those participating in the meal programme were likely more representative of individuals already utilizing library resources as opposed to individuals who specifically came to the library for the meal programme.

\section{Conclusion}

Despite these limitations, our findings provide a first examination of a library-based approach to addressing FI. Our findings demonstrate the need for innovative communitybased summer meal programmes that target hard-to-reach low-income children, particularly those living in areas where high economic disparities persist. Given the difficulty that individuals face accessing and utilizing community and public food resources, our study suggests that public libraries offer a highly trusted place to provide both meals and access to information regarding other programmes and services. As experts in the field continue to call for the expansion of summer food programmes to ease the FI burden among children during the summer months ${ }^{(25)}$, library-based meal programmes are well poised to heed this call to action.

\section{Acknowledgements}

Acknowledgements: The authors would like to thank Cindy McCown, Tometrius Paxton, Susan Takalo and Jessica Valdez (Second Harvest Food Bank), Elena Valle and Carine Risley (San Mateo County Library), Michelle Amores (San Jose Public Library) and Jennifer Puthoff (YMCA Silicon Valley) for their support in the development and implementation of this study. They would also like to thank Kimmy Phan and Lydia Demissachew for their assistance in data collection, transcription and translation. Financial support: This work was supported by Second Harvest Food Bank, ConAgra Foods Foundation, and the Lucile Packard Children's Hospital Stanford, Community Benefits. The funders had no role in the design, analysis or writing of this article. Conflict of interest: The authors have no conflicts of interest to disclose. Authorship: J.S.B. and M.M.D.L.C. formulated the research question and designed the study; J.S.B. and M.M.D.L.C. carried out the study; J.S.B., M.M.D.L.C. and G.M. analysed the data; and J.S.B. and M.M.D.L.C. wrote the article. L.J.C. provided mentorship and oversight of the study. Ethics of human subject participation: This study was conducted according to the guidelines laid down in the Declaration of Helsinki and all procedures involving human subjects were approved by the Stanford University Institutional Review Board. A waiver of documentation for consent was granted by the Stanford Institutional Review Board. All subjects provided verbal informed consent which was witnessed and formally recorded.

\section{References}

1. Gundersen C (2013) Food insecurity is an ongoing national concern. Adv Nutr 4, 36-41.

2. Oberg CN (2011) The Great Recession's impact on children. Matern Child Health J 15, 553-554.

3. Coleman-Jensen A, Rabbitt MP, Gregory CA et al. (2016) Household Food Security in the United States in 2015. Economic Research Report no. ERR-215. Washington, DC: US Department of Agriculture, Economic Research Service; available at https://www.ers.usda.gov/webdocs/publications/ err215/err-215.pdf

4. Alaimo K, Briefel RR, Frongillo EA Jr et al. (1998) Food insufficiency exists in the United States: results from the third National Health and Nutrition Examination Survey (NHANES III). Am J Public Health 88, 419-426.

5. Coleman-Jensen A, McFall W \& Nord M (2013) Food Insecurity in Housebolds with Children: Prevalence, Severity, and Housebold Characteristics, 2010-2011. Economic Information Bulletin no. EIB-113. Washington, DC: US Department of Agriculture, Economic Research Service; available at https://www.ers.usda.gov/webdocs/publications/ eib113/37672_eib-113.pdf

6. Chilton M, Black MM, Berkowitz C, Casey $\mathrm{PH}$ et al. (2009) Food insecurity and risk of poor health among US-born children of immigrants. Am J Public Health 99 , $556-562$.

7. Gitterman BA, Chilton LA, Cotton WH et al. (2015) Promoting food security for all children. Pediatrics 136, e1431-e1438.

8. Defeyter MA, Graham PL \& Russo R (2015) More than just a meal: breakfast club attendance and children's social relationships. Front Public Health 3, 183.

9. Gundersen C \& Ziliak JP (2014) Childhood food insecurity in the US: trends, causes, and policy options. Future Child 24, 1-19.

10. Bartfeld J (2013) SNAP and the School Meal Program. University of Kentucky Center for Poverty Research Discussion Paper Series no. 19. http://uknowledge.uky.edu/ukcpr_papers/19/ (accessed February 2017).

11. Rose D (1999) Economic determinants and dietary consequences of food insecurity in the United States. J Nutr 129, 2 S Suppl., 517S-520S.

12. Rose D \& Oliveira V (1997) Nutrient intakes of individuals from food-insufficient households in the United States. Am J Public Health 87, 1956-1961.

13. Pollitt E (1988) Developmental impact of nutrition on pregnancy, infancy, and childhood: public health issues in the United States. Int Rev Res Mental Retard 15, 33-80.

14. Lozoff B, Jimenez E, Hagen J et al. (2000) Poorer behavioral and developmental outcome more than 10 years after treatment for iron deficiency in infancy. Pediatrics 105, e 51.

15. Rose-Jacobs R, Black MM, Casey PH et al. (2008) Household food insecurity: associations with at-risk infant and toddler development. Pediatrics 121, 65-72.

16. Murphy JM, Wehler CA, Pagano ME et al. (1998) Relationship between hunger and psychosocial functioning in low-income American children. J Am Acad Child Adolesc Psychiatry 37, 163-170.

17. Alaimo K, Olson CM, Frongillo EA Jr et al. (2001) Food insufficiency, family income, and health in US preschool and school-aged children. Am J Public Health $\mathbf{9 1}$, 781-786.

18. Cook JT, Frank DA, Berkowitz C et al. (2004) Food insecurity is associated with adverse health outcomes among human infants and toddlers. J Nutr 134, 1432-1438.

19. Stuff JE, Casey PH, Szeto KL et al. (2004) Household food insecurity is associated with adult health status. J Nutr 134, $2330-2335$. 
20. Mills G \& Hanson K (2013) Coping Strategies for Households at Risk of Childhood Hunger: Final Report submitted to the University of Kentucky Center for Poverty Research. Washington, DC: Urban Institute.

21. Whitaker RC, Phillips SM \& Orzol SM (2006) Food insecurity and the risks of depression and anxiety in mothers and behavior problems in their preschool-aged children. Pediatrics 118, e859-e868.

22. Chilton M \& Booth S (2007) Hunger of the body and hunger of the mind: African American women's perceptions of food insecurity, health and violence. J Nutr Educ Behav 39, 116-125.

23. Petterson SM \& Albers AB (2001) Effects of poverty and maternal depression on early child development. Child Dev 72, 1794-1813.

24. Gundersen C, Kreider B \& Pepper J (2012) The impact of the National School Lunch Program on child health: a nonparametric bounds analysis. J Econom 166, 79-91.

25. Gundersen C \& Ver Ploeg M (2015) Food assistance programs and child health. Future Child 25, 91-109.

26. US Department of Agriculture, Food and Nutrition Service (2016) National School Lunch Program (NSLP). http://www.fns. usda.gov/nslp/national-school-lunch-program-nslp (accessed December 2016).

27. Nord M \& Romig K (2006) Hunger in the summer: seasonal food insecurity and the National School Lunch and Summer Food Service programs. J Child Poverty 12, 141-158.

28. US Department of Agriculture, Food and Nutrition Service (2013) Summer Food Service Program (SFSP). http://www.fns.usda.gov/sfsp/frequently-asked-questions-faqs (accessed June 2016).

29. Bookey JL (2015) 8 awesome ways libraries are making learning fun. The Huffington Post, 29 June. http://www. huffingtonpost.com/jordan-lloyd-bookey/8-awesome-wayslibraries-_b_7157462.html (accessed February 2017).

30. Rooney-Browne C (2009) Rising to the challenge: a look at the role of public libraries in times of recession. Libr Rev $\mathbf{5 8}$, 341-352.

31. Veil SR \& Bishop BW (2014) Opportunities and challenges for public libraries to enhance community resilience. Risk Anal 34, 721-734.

32. Jaeger PT \& Fleischmann KR (2007) Public libraries, values, trust, and e-government. Inform Technol Libr $\mathbf{2 6}$, $34-43$.

33. Food Action Research Center (2016) Facts for Libraries: participating in summer and afterschool meals. http://frac. org/pdf/fracfacts-libraries-summer-afterschool-meals.pdf (accessed June 2016).

34. Ishuzuka K (2014) Libraries needed to host summer meal programs. Here's how to help. School Library Journal, 7 July. http://www.slj.com/2014/07/programs/libraries-nee ded-to-host-summer-meal-programs-heres-how-to-help/\# (accessed February 2017).

35. UCLA Center for Health Policy Research (2013) CHIS 20132014 Questionnaires. http://healthpolicy.ucla.edu/chis/ design/Pages/questionnairesEnglish.aspx (accessed April 2015).

36. Hager ER, Quigg AM, Black MM et al. (2010) Development and validity of a 2 -item screen to identify families at risk for food insecurity. Pediatrics 126, e26-e32.

37. Patton M (1990) Purposeful sampling. Qual Eval Res Method 2, 169-186.

38. Fonteyn ME, Vettese M, Lancaster DR et al. (2008) Developing a codebook to guide content analysis of expressive writing transcripts. Appl Nurs Res 21, 165-168.

39. Bertrand JT, Brown JE \& Ward VM (1992) Techniques for analyzing focus group data. Eval Rev 16, 198-209.

40. Krueger RA (1994) Focus Groups: A Practical Guide for Applied Research, 2nd ed. Thousand Oaks, CA: SAGE Publications, Inc., pp. 232-235.
41. Ryan GW \& Bernard HR (2003) Techniques to identify themes. Field Method 15, 85-109.

42. Fereday J \& Muir-Cochrane E (2006) Demonstrating rigor using thematic analysis: a hybrid approach of inductive and deductive coding and theme development. Int J Qual Method 5, 80-92.

43. Malterud K (2001) Qualitative research: standards, challenges, and guidelines. Lancet 358, 483-488.

44. Kirkpatrick SI \& Tarasuk V (2007) Adequacy of food spending is related to housing expenditures among lower-income Canadian households. Public Health Nutr 10, 1464-1473.

45. Nord M \& Kantor LS (2006) Seasonal variation in food insecurity is associated with heating and cooling costs among low-income elderly Americans. J Nutr 136, 2939-2944.

46. Hanratty MJ (2006) Has the Food Stamp Program become more accessible? Impacts of recent changes in reporting requirements and asset eligibility limits. J Policy Anal Manage 25, 603-621.

47. Schanzenbach DW (2009) Experimental Estimates of the Barriers to Food Stamp Enrollment. Madison, WI: Institute for Research on Poverty.

48. Herd P (2015) How administrative burdens are preventing access to critical income supports for older adults: the case of the Supplemental Nutrition Assistance Program. Public Policy Aging Rep 25, 52-55.

49. Ratcliffe C, McKernan S-M \& Finegold K (2007) The Effect of State Food Stamp and TANF Policies on Food Stamp Program Participation. Washington, DC: Urban Institute.

50. Fix ME \& Passel JS (1999) Trends in Noncitizens' and Citizen's Use of Public Benefits Following Welfare Reform, 1994-97. Washington, DC: Urban Institute.

51. Kaushal N, Waldfogel J \& Wight V (2013) Food insecurity and SNAP participation in Mexican immigrant families: the impact of the outreach initiative. B EJ Econom Anal Policy 14, 203-240.

52. Ng'andu J \& Leal Gianfortoni EM (2006) Sin Provecho: Latinos and Food Insecurity. NCLR Nutrition Report 2006. http://graphics8.nytimes.com/images/blogs/thelede/posts/ La_Raza_Summ.pdf (accessed February 2017).

53. US Citizenship and Immigrant Services \& Institute of Museum and Library Services (2005) Library Services for Immigrants: A Report on Current Practices. https://www. uscis.gov/sites/default/files/USCIS/Office of Citizenship/ Citizenship Resource Center Site/Publications/G-1112.pdf (accessed June 2016).

54. Burke SK (2008) Use of public libraries by immigrants. Ref User Serv $Q$ 48, 164-174.

55. Kaye L, Lee E \& Chen YY (2013) Barriers to food stamps in New York State: a perspective from the field. J Poverty 17, 13-28.

56. Bartlett S, Burstein N \& Hamilton W (2004) Food Stamp Program Access Study: Eligible Nonparticipants. Washington, DC: US Department of Agriculture, Economic Research Service; available at https://www.ers.usda.gov/webdocs/publications/ efan030132/30616_efan03013-2fm_002.pdf

57. Luo L, Estreicher D, Lee PA et al. (2012) Social workers in the library: an innovative approach to address library patrons' social service needs. Qual Quant Method Libr 1, $73-82$.

58. Levedahl JW (1995) How much can informational outreach programs increase food stamp program participation? Am J Agric Econ 77, 343-352.

59. Zhu L \& Xu P (2015) The politics of welfare exclusion: immigration and disparity in Medicaid coverage. Policy Stud J 43, 456-483.

60. Watson $\mathrm{T}$ (2014) Inside the refrigerator: immigration enforcement and chilling effects in Medicaid participation. Am Econ J Econ Policy 6, 313-338.

61. Feinberg S \& Schull DD (2001) Family place libraries: transforming public libraries to serve very young children and their families. Zero Three 21, 4-7. 